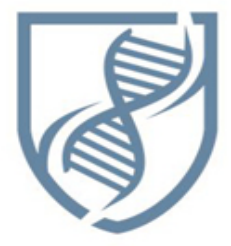

Journal of Bioscience and Applied Research

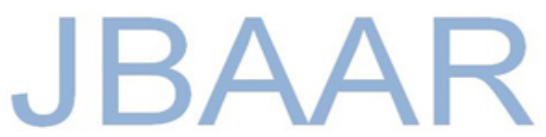

WWW.JBAAR.ORG

\title{
Effect of noise on blood pressure and heart rate for some workers in Missan governorate, Iraq
}

\author{
Abbas,Ch. Mraissl ${ }^{1}$, Haitham, H. Abd ${ }^{2}$, Nadhm , A. Kalf ${ }^{\curlyvee}$ \\ 1. Pathology /Basic medical science/ Nursing College / Missan University \\ 2. Environmental studies /Biology /Ministry of Education / Al-Anbar,Iraq
}

\begin{abstract}
The noise has become a very important (stress factor) for the human community especially in industrial cities. The aim of this study was to investigate the relationship between occupational noise level with arterial blood pressure (systolic and diastolic), heart rate, pulse pressure, mean arterial pressure for some workers from industrial region (Black smiths, Lath machine), Generators and Grinders. The data were collected between (The first of November -2015 to the Thirty of January -2016).The study group included (60) workers in various professions and exposed to the industrial noise levels with mean (97.25dB), with mean age (30.35) years and mean weight (72.46) $\mathrm{Kg}$ and mean height (168.86) cm. The control group consist of (30) subjects with mean age (31.45) years and mean weight (66.37) $\mathrm{Kg}$ and mean height $(162.93) \mathrm{cm}$. taken from students and staff members of Missan university with some donors who never lived or worked in noisy environment. The results of this study showed significant changes in $(\mathrm{P}<0.05)$ for systolic and diastolic blood pressure, heart rate, pulse pressure , mean arterial pressure in the workers for all occupations .

It is concluded from this study that the industrial noise could be causal factor for cardiovascular disturbances and increase the blood pressure and heart rate in the workers during exposure to the industrial noise.
\end{abstract}

Key words: industrial noise, systolic BP, diastolic BP, heart rate, pulse pressure.

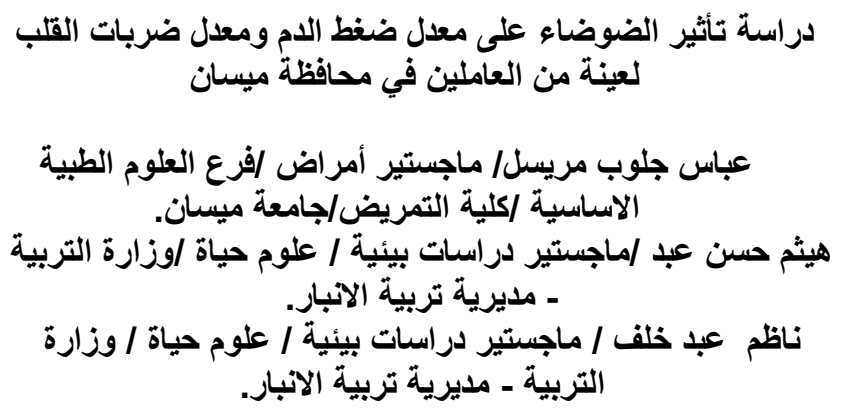

الخلاصـة:

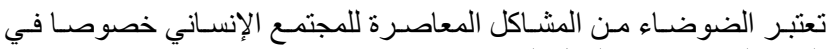

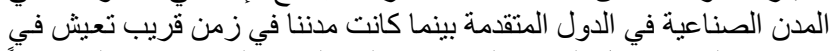

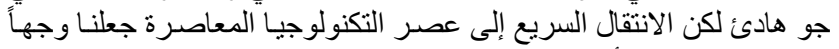

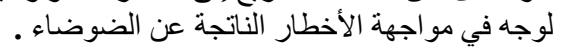

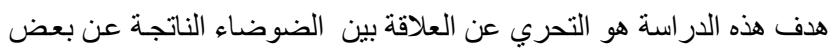

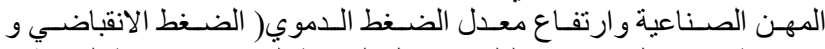

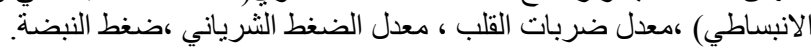

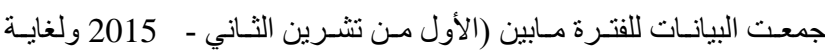

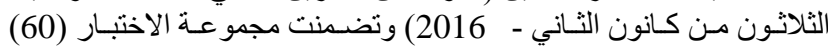

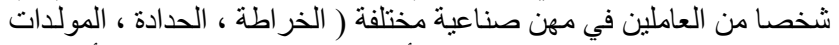

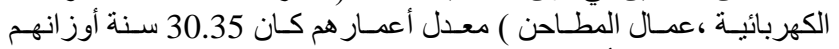

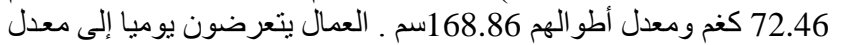

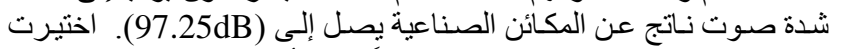

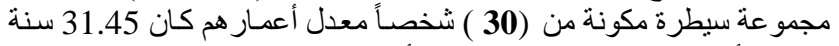

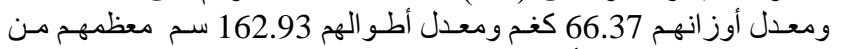

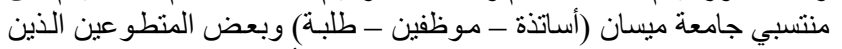

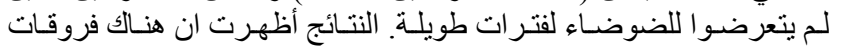

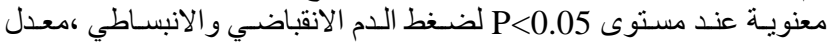

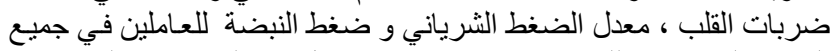

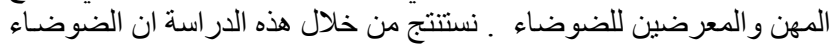

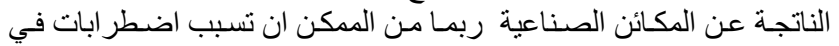

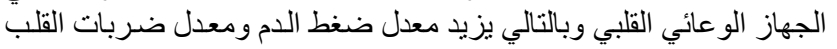
لدى العاملين المعرضين للضوضئ التئي الناتجة عن المكائن الصناعية. 


\section{Introduction المقدمة}

في ظل التقام التكنولوجي المعاصر بات من المستحيل أن تفارقنا مصادر الضجيج المختلفة المستويات بثدتها، فمنذ أن رحلت عن بئنتئنا أجوائها

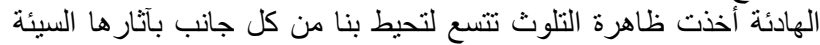

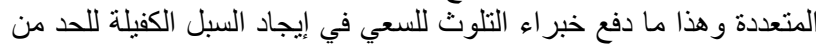

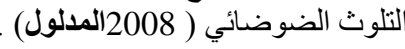

تعتبر الضوضاء من المشاكل المعاصرة للمجتمع الإنساني وتعرف بأنها

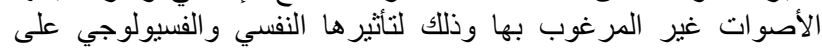

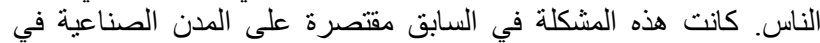

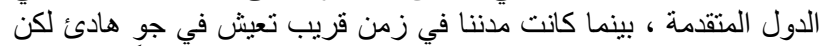

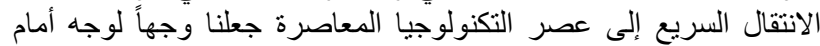

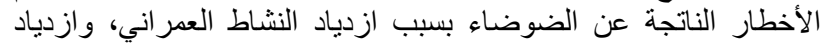

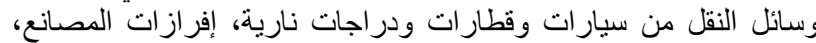

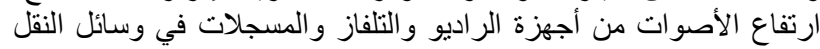
وفي البيوت مما جعل الكثير من الناس يعانون من التوتر العصبيري,

.(Kryter, 1985)

في العادة تؤثر الأصوات الدتقطعة أكثر من الأصوات الكتصلة كما

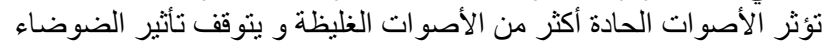

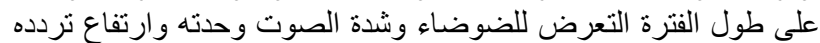

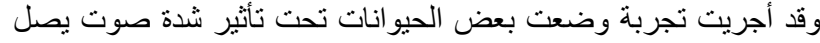

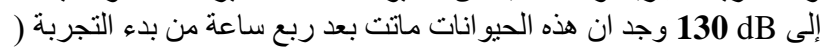

انشار(المدلول2008) أن الضوضاء قد تسبب أعراض عديدة منها

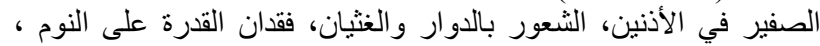

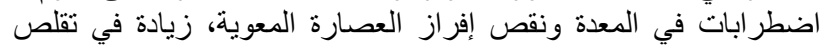

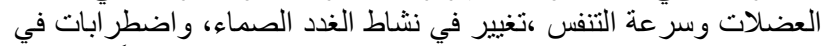

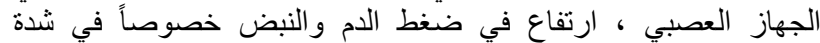

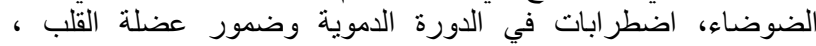
اضطر ابات في مستوى الدهون و الكلوكوز في المصل.

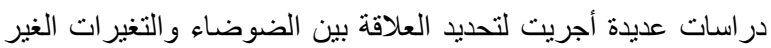

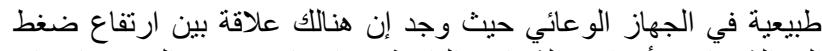

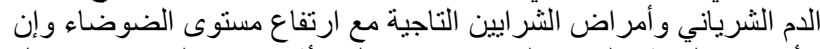

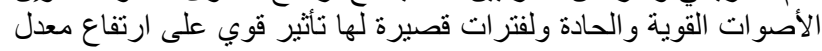

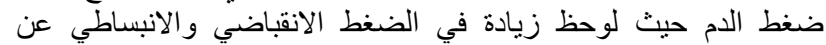
المعدلات الطبيعية عند التعرض لثدة صوت لثن تصل إلى (90dB) لمدة

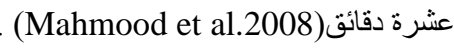

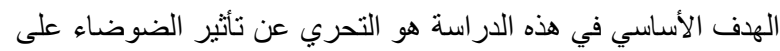

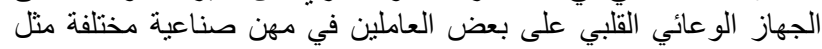

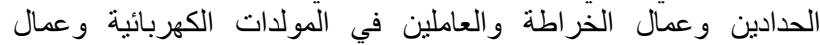

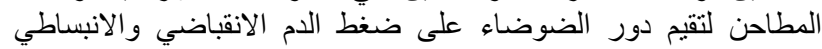
ومعدل ضربات القلب وضغط النبضة ومعدل الضغط الشرياني.

\section{The material and methods المواد وطرائق العمل}

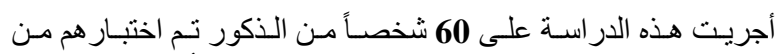

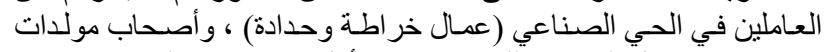

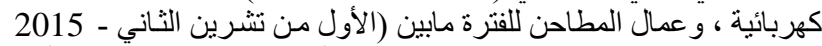

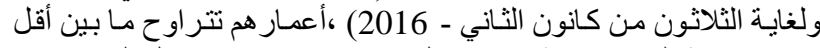

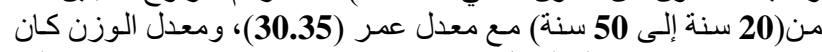

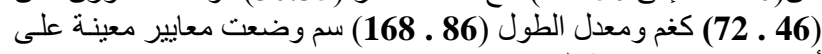
أساسها تم اختيار عينة البحث منها :

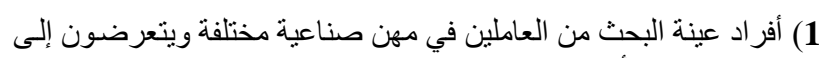
ضوضاء مستمرة أو متقطعة. 2) العاملين لم يكونو ا يعانون من ارتفاع أو انخفاض ضغنو ضغط الدم مسبقاً أو أي

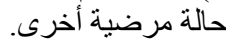

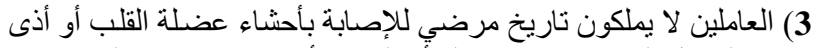

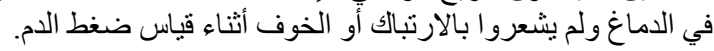

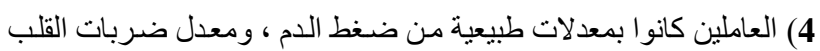

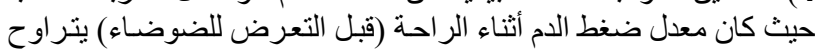

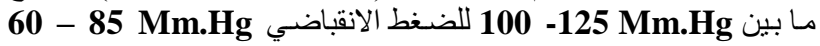
للضغط الانبساطي ومعدل ضربات القلب كان ما بين 80 - 60 نبضة في

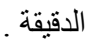

5) أفراد عينة البحث كانوا يتعرضون إلى الضوضـاء لفتترة تتراوح مـا بين

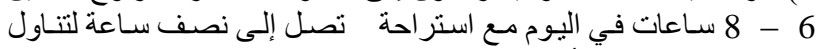
الطعام و عطلة نهاية الأسبو ليوم ليو واحد.

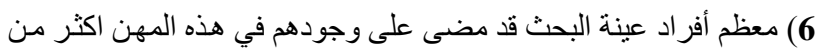
سنتين.

بما ان معدل ضـغط الدم حساس جدا ويمكن ان يتغير لعدة عو امل منهـا

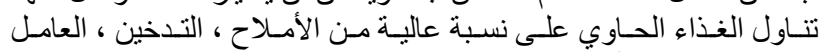

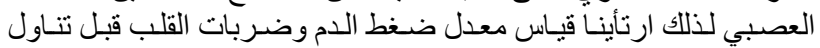

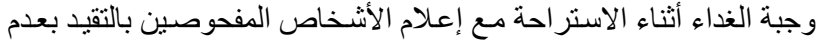
تناول الملح بكميات كبيرة والإقلال من التدخين لكي لاتؤثر على النتائج .

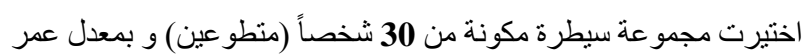

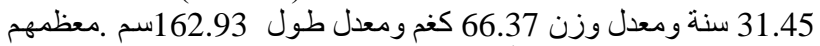
من منتسبي جامعة ميسان (أساتذة - موظفين - طلبة) وبعض المبن المتطو عين الذين لم يتعرضو اللضوضاء ملفيساء لفترات طويلة .

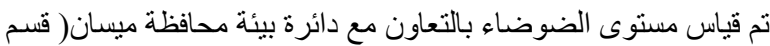

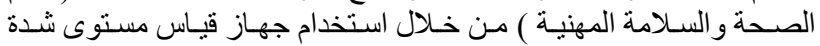
الصوت (SOUND LEVEL ADAPTER .SL . 4007) التايو اني (20)

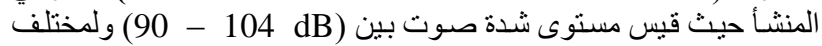

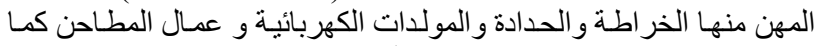

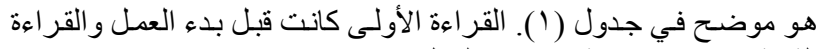

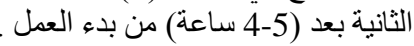

\section{قياس معدل القلب:}

تم قياس معدل ضربات القلب باستخدام الاختبار الطبي بحسب Hutchison's Clinical method (1985) من خلال منال السماح للأشخاص المفحوصين بالاستلقاء والارتخاء وذلك للإنخلص من من التعجيل

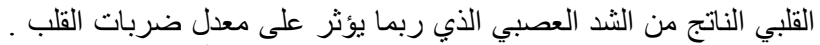

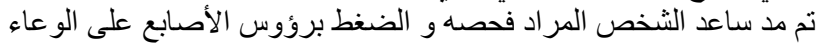

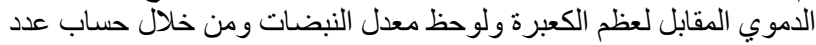

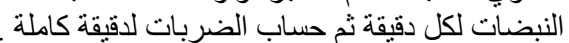

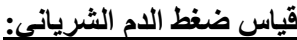

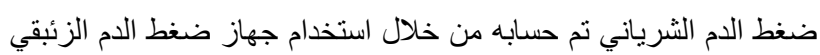
الاعتبادي وكذللك استخدام جهاز (Mercury sphygmomanometer) قاس الضغط الاموي الأكتروني من نوع (Beher type - BC 16)

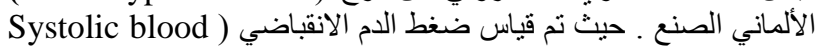

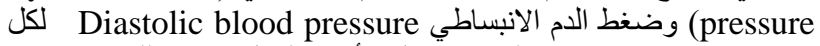

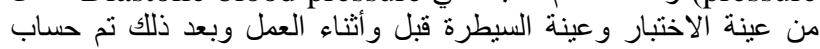

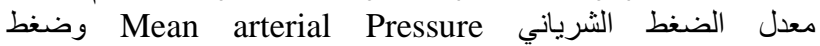
النبضة Pulse Pressure من البيانات السجلة وبالثكل التالي :

ـ ضغط النبضة = الضغط الانقباضي- الضغط الانبساطي. ـ معدل الضغط الثرياني = الضغط الانبساطي + 1/3 ضغط النبضة.

التحليل الإحصائيى:

نتائج هذه الدراسة تم تحلبلها احصائياً باستخدام اختبار

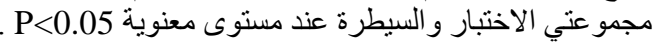




\section{The Results النتائتج}

من خلال النتائج التي تم الحصول عليها لمجموعة الاختبار المكونة من 60 شخصاً يعملون بمختلف المهن مثل (الدداة ، الخراطة ، المولدات

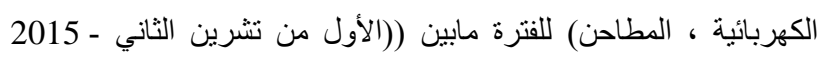

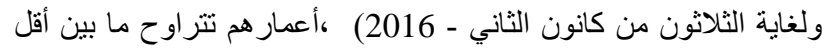

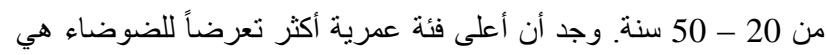

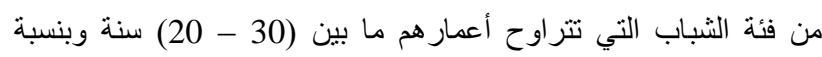

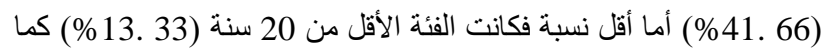

في شكل (1) (1) (1) الدراسة أظهرت أن الأشخاص الأكثر نعرضا للضوضاء هم العاملين

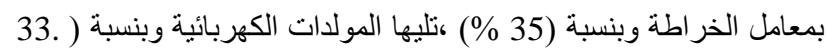

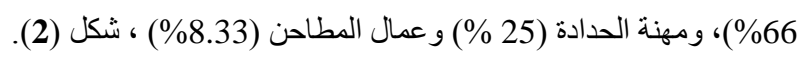

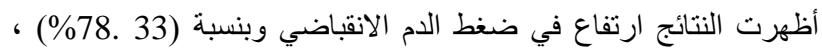

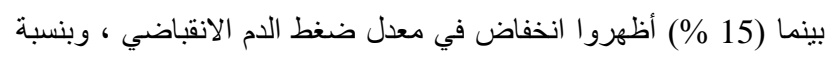

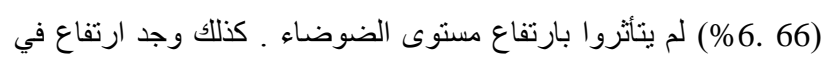
الضغط الانبساطي وبنسبة (66 \%66\%) ، بينما انخفاض الضغط الانبساطي

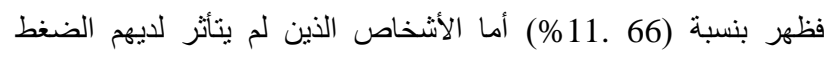

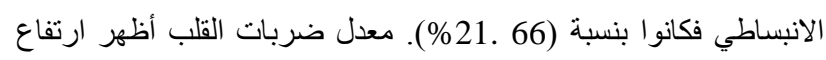

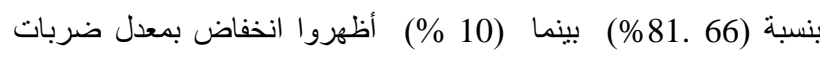

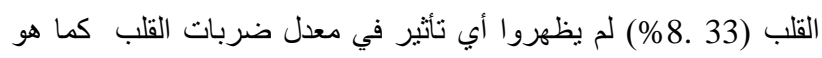
ملاحظ في الثكل ( 3 ).معدل الضغط الثرياني أظهر ارتفاع بنسبة الثرات (83.33\%) وانخفاض الضغط الثرياني وجد بنسبة (66 .11\%) ، بينما

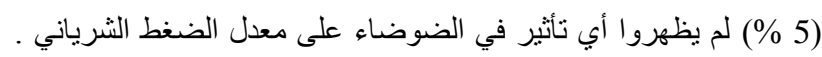
ضغط النبضة ارتفع بنسبة (60 \%) ، بينما انخفض ضغط النغ النبة

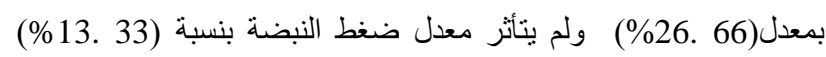
نتيجة لنأثير الضوضاء. شكل (3). النتائج أظهرت كنلك ارتفاع مستوى شدة الصوت عن الضون النسب الطبيعية

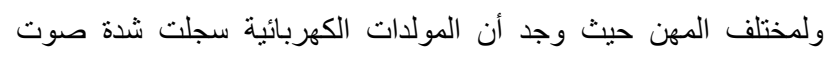
وصلت إلى (104 dB) مستمرة ، بينما أقل شدة صوت سجلت في مهنة

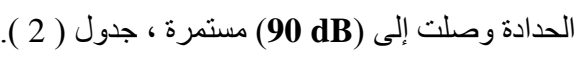

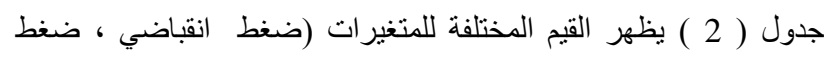

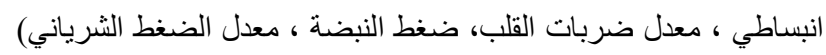
و التي يمكن أن تعبر عنها على شكل (معدل حسابي + الانحر اف المعياري)

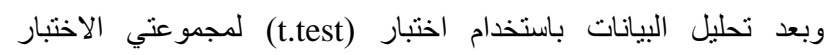

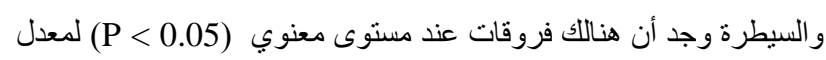
ضربات القلب لاى العاملين في معامل الخراطة والحدادة والمولدات الكهربائية كذلك وجد أن هنالك فروقات معنوية لضغط الدم الانقباضي

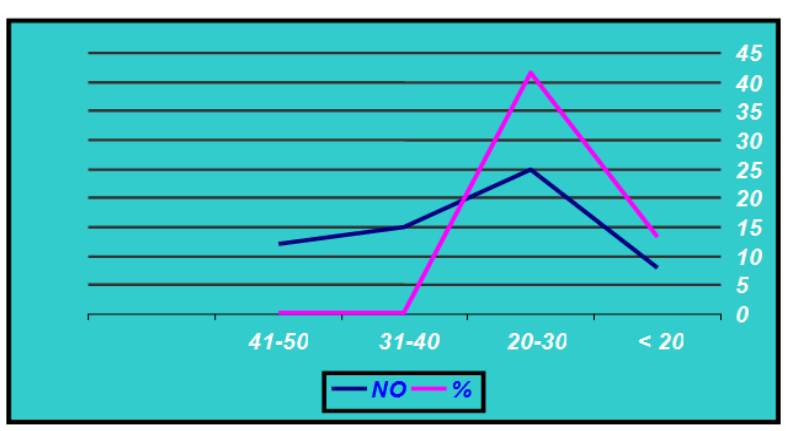

شكل (1) يبين أعداد ونسب الأشخاص الخاضعين للدراسة مبوبة حسب الأعمار [No:60 ].

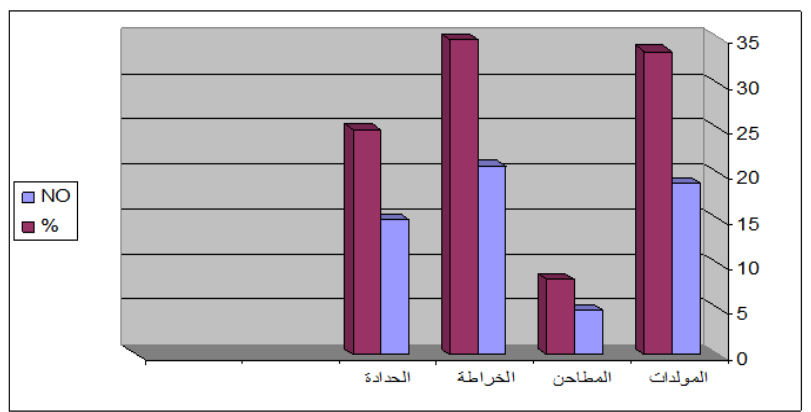

شكل (2) تبين نسب الأشخاص الأكثر تعرضا للضوضاء موزعين حسب أماكن علهم لعينة الاختبار [No:60 ].

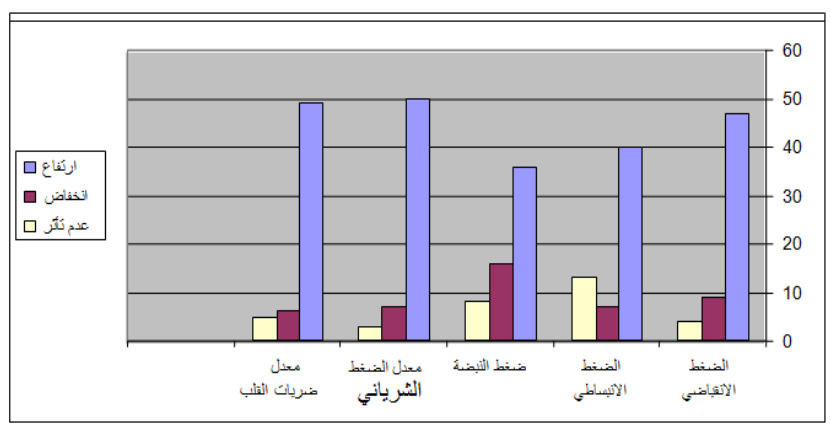

شُكل (3 ) يظهر تأثير الضوضاء على الضفط الاتقباضي ، الضغط الاتبساطي، ضغط النبضة،

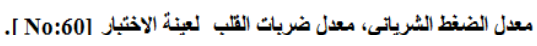

\begin{tabular}{|c|c|c|}
\hline نوع الضوضاء & مستوى شدة الصوت & مصدر الضوضاء \\
\hline مستمرة & $104 \mathrm{~dB}$ & المولدات \\
\hline مستصرة & $95 \mathrm{~dB}$ & المطاحن \\
\hline متقطعة & $100 \mathrm{~dB}$ & الذر اطة \\
\hline مستصرة & $90 \mathrm{~dB}$ & الحدادة \\
\hline
\end{tabular}

جلول ( 1) يبين مستّوى شدة الصوت المسجلة باستخدام جهاز قِياس شدة الصوت وأمختلف المهن وحسب نوع الضوضاء.

و الانبساطي وضغط النبضة ومعدل الضغط الشرياني لاءى العاملين في ناء جميع المهن . 


\begin{tabular}{|c|c|c|c|c|c|}
\hline \multicolumn{4}{|c|}{ العزية } & \multirow{2}{*}{ لمجهوعة } & \multirow{2}{*}{ المتنيرات } \\
\hline المطاحن & نولداتاتكريائية & الحدادة ل الح & الخراطة & & \\
\hline 5 & 19 & 15 & 21 & 30 & انعسلة \\
\hline $143 \pm 1.34$ & $134.7 \pm 7.34$ & $134.4 \pm 4.31$ & $145.6 \pm 4.07$ & $116.73 \pm 6.99$ & ضغط ألدد الآقباضي \\
\hline $95.6 \pm 0.70$ & $83.7 \pm 3.32$ & $88.4 \pm 4,23$ & $91.3+7.95$ & $77 \pm 4.42$ & ضغط أند الأبساطي \\
\hline $47.3 \pm 0.56$ & $50 \pm 2.34$ & $46.2 \pm 0.72$ & $54.3 \pm 1.3$ & $39.73 \pm 5.09$ & ضغط النبضة \\
\hline $111.3 \pm 0.96$ & $103.3 \pm 1.1 .44$ & $103.7 \pm 1.40$ & $109.4 \pm 8.84$ & $90.17 \pm 5.09$ & معل الضنط النشريانى \\
\hline $82.4+8.96$ & $89.47+20.52$ & $92.6+32.36$ & $87.76+8.69$ & $77.13+3.74$ & معل ضر بات القب \\
\hline
\end{tabular}

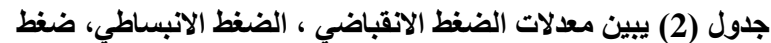

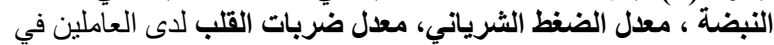

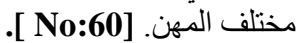

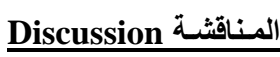

في السبعينات من القرن الماضي وضعت منظمة الصحة و السلامة المهنية معايير لمستوى الضوضاء التي من الممكن أن يتعرض لها العاملين والتي حددت بمقدار (90 dB) كأقصى حد دون استخدام واقيات الأذن

ولمدة ثمان ساعات في اليوم (Diserns,1974). من خلال نتائج التي تم الحصول عليها في هذه الدراسة وجد أن الفئات العمرية الأكثر تعرضاً للضوضاء الناتجة عن مكان العمل هي فئة الثباب الذين تتراوح أعمار هم (20 - 30) سنة ولمختلف المهن (الخراطة ،

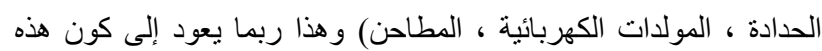
الفئة هي الأكثر اشتغالاً في هذه المهن الصعبة التي تحتاج إلى قوة عضلية وذهنية. در اسة أجريت في اليابان من قبل Sawada (1993) وجد أن هنالك ارتفاع في معدل الضغط الدموي ومعدل ضربات القلب لدى الرجال من فئة الثباب عند التعرض للضوضاء، بينما ( Harrison and Kelly1989) وجدوا أن هنالك تأثير معنوي للضوضاء على الجهاز الوعائي القلبي للأعمار الكبيرة بالمقارنة مع فئة الثباب عند التعرض إلى مستوى شدة صوت تصل إلى (80 dB)

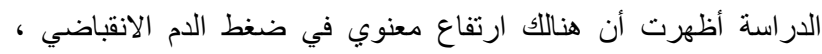

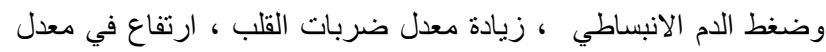
الضغط الثرياني ، ارتفاع في معدل ضغط النبضة لإى العاملين المعرضين للضوضاء ، كما هو موضح في شكل (3). هذه النتائج تو افق ما أشار إليه (Singhal et al.2009) وجماعته أن هناك ارتفاع في ضغط الدم الانقباضي و الانبساطي ومعدل ضربات القب ومعدل الضغط الثرياني وضغط النبضة في الدراسة أجريت على (114) شخص من العاملين في بعض المصانع المغلقة في مدينة علي كاره في الهند ويتعرضون لمستوى وضئ شدة صوت ناتجة عن عمل الآلات قد تصل إلى (104 dB) ولمدة ثمان ساعات ـ و استتتجوا من ذلك أن الضوضاء الناتجة عن المكائن الصناعية ربما من المكن أن تعتبر كعامل مساهم في تطور ارتفاع الضغط الشرياني. دراسة أجريت في الأرض المحتلة من قبل (Meamed et al.1993)

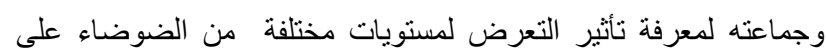

العاملين في المصانع وعلاقتها بطبيعة المهنة ، حيث وجد أن هنالك ارتفاع في مستوى الضغط الانقباضي ومعدل الضغط الشرياني ،وضغط النبضة ، وزيادة معدل ضربات القلب للأشخاص العاملين في مهن معقدة Complex

Simple jobs بالمقارنة مع الأشخاص العاملين في مهن بسيطة jobs دراسة أخرى أجريت من قبل (Rosenlund 2001) على مجمو عتين من الناس أحدهما تعيش بالقرب من مطار ستوكهولم والأخرى بعيدة عن من فئ المطار، وجد أن (80 \%) من الأشخاص الذين يعيشون بالقرب من مدرج

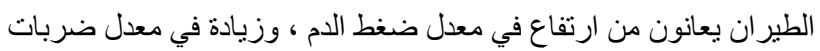

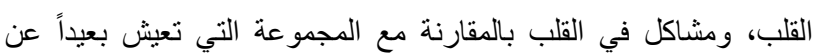
المطار. جدول (1) أظهر ارتفاع لمستوى شدة الصوت الناتج عن المعدات والآلات الخاضعة للار اسة (الخراطة ، الحدادة ، المولدات الكهربائية ، المطاحن) وبفارق (dB dB 25 ـ 7) عن المعدلات القباسية التي وضعت من قبل منظمة

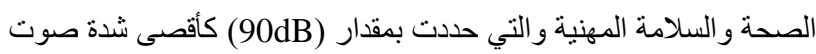
من الممكن التعرض إليها ولفترة قصيرة ، حيث أن معدل مستوى شدة الصوت الذي سجل في هذه الدر اسة كان (97. 25dB).

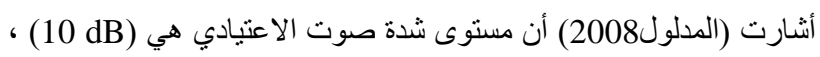

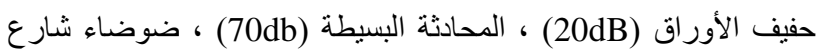

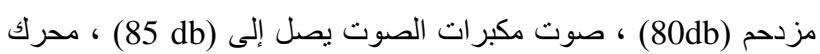

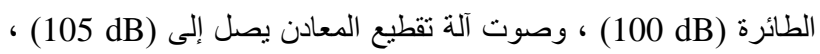
صوت مناشير الخشب يصل إلى (105 dB) ، صوت المطارق السريعة

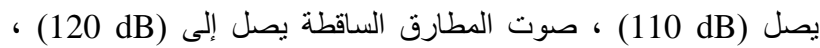

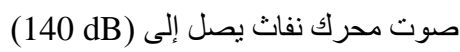
أن الميكانيكية المسؤولة عن ارتفاع معدل الضغط الدموي ومعدل ضربات القلب عند التعرض للضوضاء لم تفهم لحد الآن، ولكن هناك بعض العو امل التي قد تلعب دوراً مهماً في ارتفاع الضغط الدموي وزيادة المقاومة المحيطية للشريان كرد فعل انعكاسي خلال التعرض للضوضاء المستمرة و المتقطعة ومن هذه العوامل هو انطلاق الكاتيكو لامين Catecholamine من الغدة الكظرية كنتيجة لتنشيط Adrenergic System وبالتالي يؤدي إلى تقلص في الأوعية الدموية وزيادة الضغط الدموي على جدران الأوعية الدموية (Babisch et al.1990) . Harris الممكن أن يسبب ارتفاع في ضغط الدم وبالتالي يزيد من احتياج القلب إلى إلى

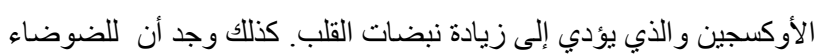
تأثير على جدران الأوعية الدموية من خلال تأثيرها على الجهاز الودي

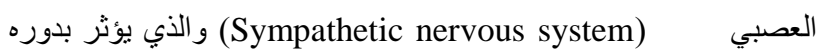
على معدل ضغط الدم ومعدل ضربات القلب خلال زيادة المقاومة المحيطية للأو عية الدموية وزيادة تقلصها وكذلك تقلص عضلة جدار القلب ( Fisher . (and Trucker,1991 
أشار(Lesnik et al.1989) إن التحفيز المتكرر للضوضاء على الثريان

الدموي ربما يعمل على إجراء تغييرات نركيبية وعائية في المقاومة

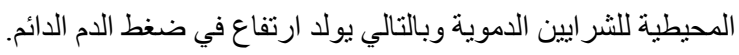
كذلك أكد (1991, Fisher and Tucker) وجماعته أن هناك زيادة

في ضغط الدم وزيادة في الطرح الكلوي لمادة Epinephrine و epinephrine

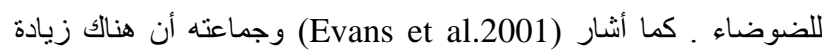
ثمان ساعات لطرح الإدرار الحاوي على الكورتزول خلال الليل لاى الأطفال الذين يعيشون في بيئة عالية الضوضاء. واستناداً إلى هذه الحقائق يمكن أن نستدل إن الضوضاء قد تكون مرتبطة بزيادة تحفيز الجهاز الصماوي العصبي Nenroendocrine system ينتج عنه زيادة في بري الضغط الدموي ومعدل ضربات القلب .

نستنتج من هذه الدراسة ان الضوضاء الناتجة عن المكائن الصناعية ربما من الممكن ان تسبب اضطرابات في الجهاز الوعائي القلبي للعمال

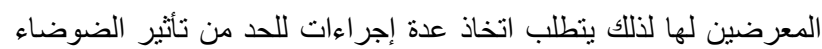

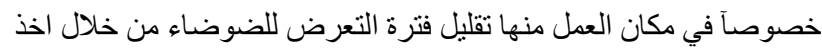
فترة راحة بين فترة وأخرى أثناء العمل ، كذلك السيطرة على مصادر

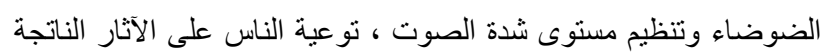
عن التلوث الضوضائي وإصدار قوانين تعاقب من يتجاوز على الفضاء

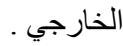

\section{:The References المصادر}

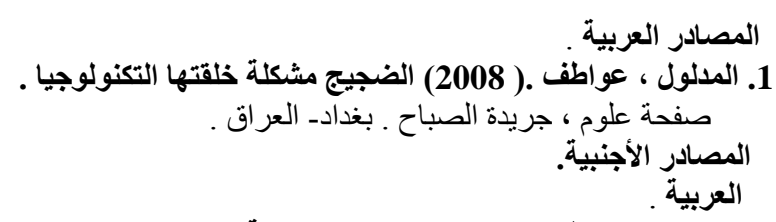

1. المدلول ، عواطف .( 2008) الضجيج مشكلة خلقتها التكنولوجيا .

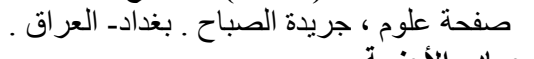

BabischW, Ising H, Gallacher JE, Sharp DS, Baker IA.(19903).Traffic noise and cardiovascular risk , first phase . Arch Environ Health ; 48:401-405

Diserns AH. (1974) . Personal noise dosimetry in refinery and chemical plants .J Occup Med ; 16(4):255-7.

Evans GW, Lercher P, Meis M, Ising H, Kofler WW. (2001). Community noise exposure and stress in children . J Acoust Am ;109 (3):1023 -7.

Fisher LD, Tucker DC.(1991).Air jet noise exposure rapidly increases blood pressure in young borderline hypertensive rates . J Hypertens ;9(3):275- 82.

Harris,H.(1979). Hand book of noise control . New York :Mc Graw- Hill Inc.
Harrison DW, Kelly PL.(1989). Age difference in cardiovascular and cognitive performance under noise conditions . Percept Mot Skills; 69(2):547 -54.

Kryter KD. (1985) . The effect of noise on Man . New York . Academic Press; pp389-393.

Lesnik H, Makowiec Dabrowsks T .(1989).

Hemodynamic reactions to monotonous work performed in silence and in noise of $70 \mathrm{Db}$. Pol J Occupt Med ; 2(1):51- 61 .

Mahmood R, Parveen N, Jilani G, Rahman J, ulHaq A , ulHaq I. ( 2008). Cardiovascular effects of short term noise of a constant frequency and intensity . Pak J Physiol ; 4 (2):20-23

Melamed S, Harari G, Green MS.(1993). Type A behavior , tension, and ambulatory cardiovascular reactivity in workers exposed to noise stress . Psychosom Med; 55(2):185 -92.

Rosenlund M.(2001). Aircraft Noise Linked to high blood pressure . Occup Environ Med ; 58:761-73.

Sawada Y. ( 1993) . Reproducible increase in blood pressure during intermittent noise exposure . Eur J Appl Physio ; 67( 4) : 367- 74.

Singhal S, Yadav B, Hashmi SF, Muzammil MD.(2009). Effects of workplace on blood pressure and heart rate .Bio Med search , Aligarh Uni.India .

The cardiovascular system (Ch9) in Hutchison's Clinical methods .(1985). The $18^{\text {th }}$ ed . ELBS ., Great Britain : PP198-263 